\section{Titar V., Shpachenko O., Panimarchuk 0., Guzenko M., Koshman 5. Lutsky $\mathbf{5}$.}

\title{
DEVELOPMENT OF A LASER COMPLEX FOR ECOLOGICAL MONITORING OF THE ATMOSPHERE OF URBAN AND INDUSTRIAL AREAS
}

The object of research is methods of remote ecological monitoring of the surface layer of the atmosphere within residential areas and industrial zones of big cities. For the remote determination of the quantitative characteristics of gas and aerosol air pollution with high accuracy and spatial resolution, a mobile laser complex has been proposed. Determination of the composition and concentration of gas pollutants is carried out using two methods - the differential absorption method and the spontaneous Raman scattering (SRS) method. The differential absorption method is used to detect low concentrations of polluting gases along a stationary sounding path. The spontaneous Raman scattering method is used for remote detection of harmful gaseous substances at their concentrations exceeding the maximum permissible standards. SRS method used in the developed gas aerosol lidar allows one to obtain three-dimensional distributions of the concentrations of the gases being determined with a resolution of the order of one meter. This makes it possible to quickly and accurately identify environmentally hazardous sources of air pollution and reasonably apply penalties to violators of environmental standards. Remote analysis of the aerosol composition of the surface layer of the atmosphere is carried out using lidar holography methods, which were developed in the laboratory of radio and optical holography of V. N. Karazin Kharkiv National University (Ukraine). The difference in reflection from liquid and solid aerosol particles makes it possible to form polarization holograms and consider them separately for liquid and solid aerosols. Quantitative analysis of the composition and concentration of particles observed from their holographic images is characterized by a high level of sensitivity, since, unlike other known methods, it does not require a priori assumptions about the qualitative composition of the determined aerosol. Thus, due to the use of various physical principles of the interaction of laser radiation with gaseous and aerosol components of the air, the developed laser complex for environmental monitoring of the atmosphere is an effective means of monitoring the state of the air in the conditions of modern megacities.

Keywords: laser sounding of the atmosphere, differential absorption, spontaneous Raman scattering, gas aerosol holographic lidar.

Received date: 03.04 .2020

Accepted date: 22.05 .2020

Published date: 31.08 .2020
Copyright (C) 2020, Titar V., Shpachenko O., Panimarchuk O., Guzenko M., Koshman S., Lutsky S. This is an open access article under the CC BY license (http://creativecommons.org/licenses/by/4.0)

\section{Introduction}

The widespread use of fossil fuels such as oil, coal, gas in industry, transport and in everyday life leads to the emission of an ever-increasing amount of gaseous and aerosol pollutants into the atmosphere. These substances affect natural physical and chemical processes in nature, the life of animals and, especially, people. Humanity feels the harmful effects of atmospheric pollution in the form of acid rain, the deposition of toxic industrial waste, and the appearance of photochemical smog in industrial areas.

The problem of the ecological state of the atmosphere in industrial centers was significantly aggravated in connection with the continuous motorization that took place in European states. Automobile transport is one of the most dangerous sources of air pollution. Today, emissions from vehicles prevail over emissions from stationary sources, with a ratio of $60: 40 \%$ or more.

Under traditional monitoring, dozens of pollutants remain «uncontrolled», including such hazardous ones as polycyclic aromatic hydrocarbons PAHs (benzene, benzpyrene, toluene, etc.), formaldehydes, chlorine-containing substances, ozone (the special toxicity of which increases in the presence of nitrogen oxides 20 times). Especially dangerous toxic substances are formed in the atmosphere also in secondary reactions during the chemical interaction of pollutants emitted from man-made sources under the influence of solar radiation (transformation processes).

In connection with the constantly increasing anthropogenic pollution of the Earth's biosphere, the development and implementation of the latest methods of environmental monitoring is becoming increasingly important. 


\section{The object of research and its technological audit}

The object of research is methods of remote ecological monitoring of the surface layer of the atmosphere within residential areas and industrial zones of big cities.

The most complete modern requirements for the promptness of obtaining information about the state of the atmosphere are met by laser sensing methods capable of providing remote monitoring of a given section of airspace in real time. For this purpose, the laboratory of radio and optical holography of V. N. Karazin Kharkiv National University (Ukraine) has developed a laser complex for environmental monitoring of the state of the atmosphere in large industrial centers. The complex consists of two mobile units. One of the installations is a laser differential absorption gas analyzer (LDAG) designed to determine the integral concentration of the main gas pollutants along selected stationary routes. The second mobile unit is a gas-aerosol holographic lidar (GHL), one of the channels of which allows one to determine the concentration of a wide range of atmospheric gases by spontaneous Raman scattering (SRS), and the second channel is designed to determine the type and concentration of aerosols by holographic methods.

The proposed laser complex allows for comprehensive environmental monitoring of the atmosphere in the zone of residential urban development and in the sanitary protection zone of enterprises according to its actual state in combination with accurate accounting of the composition and power of emissions from man-made sources. With the help of the proposed laser complex, it is possible to obtain a reliable assessment and forecast of the likely development of man-made situation at the stage of critical parameters of pollution for taking preventive measures in order to prevent environmental disasters.

\section{The aim and objectives of research}

The aim of research is to develop schematic diagrams for the technical implementation of the selected optimal methods of laser sensing and in a set of measures for environmental monitoring of the surface layer of the atmosphere in urban and industrial areas. To achieve this aim, it is necessary to complete the following tasks:

1. Justify the choice of physical principles of interaction of laser radiation with atmospheric components, which will be optimal for determining the level of concentration of pollutants in various zones of urban areas, taking into account the proximity of industrial facilities.

2. Evaluate the efficiency of using the developed schemes by means of computer simulation of the process of detecting the most common polluting gases during sounding of the atmosphere with laser pulses.

3. Describe the basic principles of metrological support of the information processing system in the created laser complex for environmental monitoring of the surface layer of the atmosphere.

\section{Research of existing solutions of the problem}

Quite a lot of works have been devoted to the issues of remote laser sensing of the atmosphere in order to determine its individual components. So, the importance of the problem of monitoring the state of the environment and the use of lasers for remote environmental monitoring of the state of the atmosphere are reflected in [1]. And in [2] it is noted that there are many methods for detecting pollutants: infrared spectroscopy, electrochemistry, gas chromatography, etc. Each of these methods has its own advantages and disadvantages. It is emphasized that the methods of laser sensing (lidar methods) are remote and do not require the collection of chemical samples for analysis, which in many cases is a significant advantage.

In [3], a brief history of the development of lidars (English lidar - «light detection and ranging» - «detection and determination of range using light») and their application in atmospheric research is presented. It is emphasized that every year lidar systems are becoming more and more sophisticated, so that now it has become possible to widely use them in practice for monitoring pollution.

In laser sensing, the following effects of interaction of a light wave with a medium are mainly used: aerosol and molecular scattering, fluorescence, spontaneous Raman scattering, and resonance absorption [3, 4].

In [5], an overview of the existing differential absorption lidars is given. It is noted that the differential absorption method is mainly used in ground and airborne lidars to measure the concentration of tropospheric and stratospheric ozone and tropospheric water vapor. It is reported that work has begun on the development of a differential absorption lidar for integrated high-precision measurements of $\mathrm{CO}_{2}$ and $\mathrm{CH}_{4}$ along the sounding path.

In [6], information is given on preliminary tests of a differential absorption lidar based on board a research aircraft. Lidar is designed to determine the integral concentration along the sounding path of such greenhouse gases as $\mathrm{CO}_{2}$ and $\mathrm{CH}_{4}$.

The works [7, 8] report the creation of ground-based twolidar systems based on the differential absorption method. The IPDA (integrated path differential absorption) laser system developed by the authors allows measuring low concentrations of $\mathrm{CO}_{2}, \mathrm{CH}_{4}$, and $\mathrm{H}_{2} \mathrm{O}$, averaged over the sounding path. In this case, to obtain information about the concentration of the substances under study, laser radiation is used, reflected in the opposite direction from topographic objects, and a tunable continuous laser is used. The created DIAL (Differential absorption lidar) laser system uses a pulsed laser and a range gating technique. In the DIAL system, atmospheric aerosol is used as a reflector distributed in space. DIAL lidar is designed to determine the distribution of $\mathrm{CO}_{2}$ and $\mathrm{H}_{2} \mathrm{O}$ concentration with a range resolution of about $250 \mathrm{~m}$.

In [7], the results of testing the ground-based differential absorption lidar developed by IPDA for measuring the average concentration of $\mathrm{CO}_{2}, \mathrm{CH}_{4}$, and $\mathrm{H}_{2} \mathrm{O}$ along the sensing path are presented. The tests were carried out at night on a $2.75 \mathrm{~km}$ track. A rock surface was used as a reflector. Tests have shown that the accuracy of measurements of the concentration of $\mathrm{CO}_{2}$ and $\mathrm{CH}_{4}$ in dry air for a measurement period of $30 \mathrm{~s}$ is $4 \mu \mathrm{mol} / \mathrm{mol}$ and $50 \mathrm{nmol} / \mathrm{mol}$, respectively.

Work [8] is devoted to testing the created DIAL lidar. Simultaneous measurements of the concentration of $\mathrm{CO}_{2}$ and $\mathrm{H}_{2} \mathrm{O}$ were carried out using DIAL and IPDA lidars, as well as a special contact $\mathrm{CO}_{2}$ and $\mathrm{H}_{2} \mathrm{O}$ sensor installed at a point on the sensing path. The contact sensor has been pre-calibrated according to the standards of the 
World Meteorological Organization (WMO). Experiments have shown that the data obtained by the DIAL lidar is consistent with the results of the IPDA and the contact probe, with an accuracy of measurement errors.

In [4], the results of preliminary tests of a small-sized prototype of an onboard scanning Raman lidar designed to detect leaks from gas and oil pipelines are presented. The tests were carried out in real conditions of the transcontinental gas pipeline and showed good results. The developed laser system is capable of detecting methane at a concentration level of $6 \mathrm{ppm}$ ( $\mathrm{ppm}$ - from the English «parts per million») and a concentration of hydrogen sulfide at a level of $2 \mathrm{ppm}$.

In [9], the creation of two types of compact Raman lidars for detecting hydrogen leaks is reported. Tests have shown that a diode-pumped Raman mini-lidar is capable of detecting hydrogen gas concentrations of $1 \%$ over a distance range of $0-50 \mathrm{~m}$ when operating in the storage mode for $30 \mathrm{~s}$. A Raman mini-lidar based on LEDs can detect $1 \%$ hydrogen concentration at distances of $0-20 \mathrm{~m}$ when operating in accumulation mode for 3.5 minutes.

Works [10,11] are devoted to the creation of a Raman (SRS) lidar for remote sensing of $\mathrm{CO}_{2}$ leakage. The conducted field measurements showed the efficiency of detecting $\mathrm{CO}_{2}$ at a distance of $0.2 \mathrm{~km}$ from the lidar installation site and good agreement of the obtained data with the data measured with the instruments on site.

The work [2] presents the results of preliminary experiments on the creation of a receiving channel of a hyperspectral Raman (SRS) lidar for geoecological monitoring. The scheme used by the authors with the use of a CCD matrix (abbreviated from «charge coupled device») will allow achieving high sensitivity and selectivity with the ability to register the spectrum of more than 100 determined chemicals online. At the same time, it is noted in [2] that the results obtained are preliminary, and further research is required for the successful development of the proposed technology.

Along with gas pollutants, when studying the ecological state of the atmosphere, it is necessary to take into account the presence of aerosol particles of natural and anthropogenic origin in it. Historically, the sounding of the atmosphere using lasers was used primarily to study not the gas composition, but the aerosol component, for example, to study the transparency of the atmosphere or the height of clouds [3].

It should be noted that the interpretation of the results of laser sensing of aerosols is more difficult than in the case of sensing the gas component. The lidar equation for aerosol is indefinite, since it contains two unknown functions - the transparency of the probed air area and the attenuation coefficient [12]. Therefore, the solution of the lidar equation for aerosol becomes possible only with the introduction of some a priori information about the investigated aerosol, as well as with the expansion of the measurement information. For example, in [13], new techniques for studying cloud media are considered using the angular properties of the multiple scattering intensity and the polarization characteristics of lidar signals reflected from aerosol particles. The authors presented a new theoretical approach with the aim of developing and creating lidars for determining the microphysical parameters of the stratospheric aerosol. However, the study of the angular properties of the reflected signal intensity is inapplicable in monostatic lidar systems in which the emitter and the receiving telescope are located on the same platform.

It is noted in [14] that probing at several wavelengths allows one to obtain information not only on the spectral dependence of the aerosol scattering coefficients, but also on the microphysical parameters of particles. The paper presents a theoretical assessment of the parameters of a multiwave lidar for aerosol monitoring in the altitude range of $1-10 \mathrm{~km}$. However, it should be noted that the use of sounding at several frequencies makes it possible to determine the parameters of the aerosol microstructure only if the aerosol consists of isotropic dielectric spheres. The assumption of sphericity and isotropy does not hold for dusty structures and industrial aerosol. For nonspherical particles, the interpretation of lidar measurements requires the introduction of additional assumptions based on information about the shape parameters of the scattering particles. Therefore, multifrequency sounding also does not guarantee the elimination of large errors in determining the countable and mass concentration of aerosol.

Analysis of the review of the literature data allows to draw the following conclusions. Remote laser sensing of the atmosphere is a very promising method of environmental control. However, the currently existing lidar systems are aimed at solving specific applied problems and therefore make it possible to determine an extremely limited amount of polluting gases. Remote laser investigation of aerosols, despite the use of various methods, does not allow one to unambiguously solve the lidar sensing equation, which leads to large errors in the interpretation of the data obtained. In addition, there is no information in the available literary sources about the development of laser systems for remote sensing of the surface layer of the atmosphere, which would make it possible to comprehensively solve the problem of determining both aerosol and gas pollution. Therefore, the development of a laser complex for environmental monitoring of the atmosphere using various physical methods of remote gas analysis in combination with fundamentally new methods of lidar holography for studying aerosols is a promising task.

\section{Methods of research}

5.1. Laser differential absorption gas analyzer (LDAG). The differential absorption method, which is used in the developed LDAG, is based on the absorption of light energy by molecules of the gas under study when the laser radiation frequency coincides with the frequency of the electronic or vibrational-rotational transition of these molecules. For the technical implementation of this method, it is necessary to carry out probing at two frequencies, one of which exactly coincides with the resonance frequency of the molecules under study, and the second differs somewhat from it (usually the difference in wavelengths is about $15 \mathrm{~nm}$ ). This is necessary to take into account the effect on the measurement results of aerosol and molecular scattering and absorption by foreign substances [15]. The method turns out to be effective in the case when the temporary accumulation mode is applied and the average concentration of the gas under study is determined along a stationary path, at one end of which a probe laser is located, and at the other end, a receiving device. If the receiver and emitter are located side by side, then a reflector is placed at the other end of the path. 
When sounding the atmosphere at two frequencies, one of which (v1) lies on the absorption line, and the other ( v2) outside it, the average gas concentration $\bar{N}$ on a path of length $z$ can be determined by the formula [16]

$$
\bar{N}=\frac{\ln K\left(J_{\mathrm{v} 1} / J_{\mathrm{v} 2}\right)}{2\left(\sigma_{\mathrm{v} 1}-\sigma_{\mathrm{v} 2}\right) z},
$$

where $K$ - the instrumental constant due to differences in laser energy, filter transmission, etc. at frequencies $v 1$ and $v 2 ; J_{v 1}$ and $J_{v 2}-$ the intensity of the received radiation at the two used frequencies after the passage of the probe pulse through the investigated layer of the atmosphere; $\sigma_{v 1}$ and $\sigma_{v 2}-$ absorption cross sections at frequencies $v 1$ and $v 2$.

To study the surface layer of the atmosphere, the differential absorption method is effective in determining the average concentrations of gases along a stationary route, when it is necessary to detect the presence of very small concentrations of the studied gas, but there is no need to determine the localization of pollution sources. This method can be effectively applied for environmental monitoring of the atmosphere in urban areas that are sufficiently remote from the production area of industrial enterprises.

A schematic block diagram of the developed LDAG is shown in Fig. 1. The absorption lines of most gases polluting the atmosphere are located in the mid-infrared range. Therefore, a CdSe-based parametric light generator (PLG) pumped by an Er:YAG laser was chosen as a source of probe radiation, which provides a smooth tuning of radiation wavelengths in the $2.8-4.2 \mu \mathrm{m}$ range. In Fig. 1 power supply unit with an Er:YAG pump laser and a tunable laser (PLG) CdSe are designated by numbers 1 and 2, respectively.

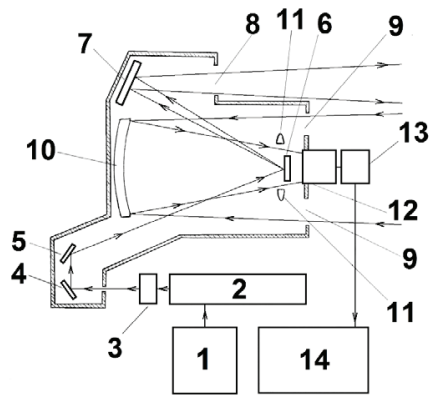

Fig. 1. Block diagram of the laser differential absorption gas analyzer (LDAG)

The use of a tunable laser allows tuning to the absorption lines of various polluting gases, due to which the amount of detected gases in the developed LDAG is structurally unlimited. However, the process of tuning the PLG to different wavelengths takes a certain time, during which the aerosol and gas composition of the atmosphere can change in a certain way. Therefore, for the «one-step» obtaining of the probe pulses at two frequencies $v 1$ and v2 (formula (1)), frequency modulation is additionally applied, carried out by the frequency modulation unit 3 .

The radiation of a tunable laser 2 , modulated in frequency using a modulation unit 3 , is fed by rotary mirrors 4,5 to the scanning mirror of the telescope 6 . The scanning mirror 6 , together with the auxiliary mirror 7 , provides the direction of the probe radiation through the exit window 8 to the desired point in space, where reflection of radiation in the opposite direction. A topographic object (a wall of a house, factory structures, etc.) is used as a distant reflector when using the LDAG to determine the average concentration of the polluting gases under study along a given area of the surface layer of the atmosphere). The radiation reflected from the topographic object passes in the opposite direction to the selected sounding path, through the input window 9 it enters the focusing mirror of the telescope 10 and, using the optical corrector 11 and the matching optical system 12, is fed to the spectrum analyzer 13 . Signals from the spectrum analyzer are transmitted to the computer 14 for further processing and visualization of the received data.

5.2. Gas aerosol holographic lidar (GHL). Gas aerosol holographic lidar is designed to determine the content of atmospheric gases by the SRS method and to determine the aerosol content using holographic methods.

The determination of the chemical composition of the atmosphere by the SRS method is based on the analysis of the spectrum of backscattered radiation, in which, in addition to the lines characterizing the incident light, additional satellite lines are observed. The difference in the frequencies of the exciting primary line and the lines of each of the satellites is a characteristic of the scattering substance and is equal to the frequencies of the natural vibrations of its molecules.

The SRS method makes it possible to determine the concentration of the gas under study using the relationship between the number of photoelectrons $P\left(z, \lambda_{R}\right)$ in the signal received by the lidar system at the SRS wavelength of the gas under investigation $\lambda_{R}$ and the concentration of this gas $N(z)$ at a distance $z$ from the lidar. This dependence is determined by the expression [17]:

$$
\begin{aligned}
& P\left(z, \lambda_{R}\right)=n_{0} K S \eta \frac{\Delta z}{z^{2}} \sigma_{R} N(z) \times \\
& \times \exp \left\{-2 \int_{0}^{z}\left[\sigma_{A}\left(\xi, \lambda_{0}\right)+\sigma_{M}\left(\xi, \lambda_{0}\right)+\right.\right. \\
& \left.\left.+\sigma_{A}\left(\xi, \lambda_{R}\right)+\sigma_{M}\left(\xi, \lambda_{R}\right)\right] d \xi\right\},
\end{aligned}
$$

where $n_{0}$ - the number of photons emitted by the lidar; $K$ - transmission coefficient of the optics of the transmitting-receiving system of the lidar; $S$ - the area of the receiving aperture of the lidar; $\eta$ - quantum efficiency of the photodetector used in the lidar; $\Delta z$ - observation interval (strobe); $\sigma_{R}-$ SRS reverse cross-section of the investigated gas component; $\lambda_{0}$ - wavelength of the probing laser pulse; $\sigma_{A}\left(\xi, \lambda_{0}\right), \sigma_{M}\left(\xi, \lambda_{0}\right), \sigma_{A}\left(\xi, \lambda_{R}\right), \sigma_{M}\left(\xi, \lambda_{R}\right)-$ coefficients of aerosol (A) and molecular (Rayleigh) (M) scattering at wavelengths $\lambda_{0}$ and $\lambda_{R}$, respectively.

The number of photons $n_{0}$ in the laser probe pulse is determined by the expression:

$$
n_{0}=\frac{W \lambda_{0}}{h c},
$$

where $h$ - Planck's constant; $c$ - speed of light; $W$ - energy in the laser pulse.

The molecular scattering coefficient depending on the wavelength $\lambda$ can be determined from the Rayleigh scattering equation as follows [18]: 


$$
\sigma_{M}(h, \lambda)=\frac{8 \pi^{3}\left(n^{2}-1\right)^{2}}{3 \lambda^{4}} \frac{\rho(H)}{N}
$$

where $n=1.00029$ - refractive index of air; $H$ - altitude above sea level of the atmospheric point at which the molecular scattering occurred; $N=2.504 \cdot 10^{25}$ - the number of molecules in one cubic meter of a standard atmosphere; $\rho(H)$ - atmosphere density coefficient.

The atmospheric density coefficient can be approximated by an exponential function [18]:

$$
\rho(H)=\exp \left(-\frac{H}{H_{0}}\right),
$$

where $H_{0}=7994 \mathrm{~m}$ is called the reduced height.

The aerosol scattering coefficient $\sigma_{A}$ in formula (2) is determined by the expression [5]:

$$
\sigma_{A}(\xi, \lambda)=\pi a^{2} Q_{S}(x)
$$

where $a$ - radius of the aerosol particle; $x=2 \pi a / \lambda-$ parameter that is used in the Mie theory and represents the size of an aerosol particle in relative units; $Q_{s}(x)$ - scattering efficiency factor.

The $Q_{s}(x)$ function is calculated using the Mie formulas and the known constants of the substance that makes up the aerosol [5].

SRS cross section $\left(\sigma_{R}\right)$ can be obtained theoretically within the framework of the quantum mechanical theory of the interaction of a system of particles with monochromatic linearly polarized light.

To determine the concentration of gas components according to formula (2), it is necessary to know exactly all the parameters included in it. However, given the fact that many coefficients in formula (2) depend on the wavelength and will be different for different gases, it is not always convenient to use this expression in practice. An important advantage of the SRS method is that the absolute concentration of gas components can be determined by comparing the intensity of satellites of the pollutants under study with the intensity of a satellite caused by one of the main atmospheric gases. A comparison is usually made with nitrogen or oxygen, the concentration of which in the surface region of the atmosphere is known and sufficiently stable over time. In this case, complex atmospheric and instrumental parameters are excluded from the equation (2) of laser ranging for SRS, and the concentration of the determined gas $N_{x}(z)$ can be calculated by the formula:

$$
N_{x}(z)=M \frac{P_{x}\left(z, \lambda_{R x}\right)}{P_{N 2}\left(z, \lambda_{R N 2}\right)} \frac{\sigma_{R N 2}}{\sigma_{R x}} N_{N 2}(z),
$$

where $M$ - instrumental constant determined by the differences in the transmittance of the optics and the sensitivity of the photodetector for the wavelengths of satellites $\lambda_{R x}$ and $\lambda_{R N 2} ; P_{x}\left(z, \lambda_{R x}\right)$ and $P_{N 2}\left(z, \lambda_{R N 2}\right)$ - the number of registered photoelectrons in SRS on the molecules of the studied gas and molecules of atmospheric nitrogen, respectively; $\sigma_{R x}$ and $\sigma_{R N 2}-$ SRS reverse cross-sections of the test gas and nitrogen; $N_{N 2}(z)$ - nitrogen concentration.

In contrast to the differential absorption method, the Raman scattering method has a slightly lower sensitivity and range (up to $2 \mathrm{~km}$ ). However, it allows one to obtain, with a high resolution (of the order of one meter), the distribution of pollutants along the sounding path and can be effective in environmental monitoring of atmospheric areas directly adjacent to industrial enterprises.

In the proposed gas-aerosol holographic lidar, the schematic block diagram of which is shown in Fig. 2, sounding of the atmosphere is performed at two frequencies. For this purpose, the radiation of a pulsed neodymium laser 1 with a wavelength of $\lambda_{0}=1060 \mathrm{~nm}$ is fed to a frequency doubler 2. After passing through a frequency doubler 2, radiation with a wavelength of $\lambda_{1}=530 \mathrm{~nm}$ is divided by a semitransparent mirror 3 into two beams, one of which is again fed to frequency doubler 4. Pulses having after frequency doubler 4 the wavelength $\lambda_{2}=265 \mathrm{~nm}$, pass through the reflective interference filter 5 to the collimator 7 and are used for gas analysis of the atmosphere by the SRS method. Radiation with a wavelength $\lambda_{1}=530 \mathrm{~nm}$, reflected from a semitransparent mirror 3 , is reflected from rotary mirrors 6 and $6^{\prime}$, is directed to the collimator 7 using a reflective interference filter 5 and is used for polarizing holographic aerosol sensing. The light scattered back by the investigated volume of atmospheric air enters the receiving telescope 8 , passes through the diaphragm 9 , the matching objective 10 and is divided into two beams by the reflective interference filter 11. Part of the light with the wavelength $\lambda_{1}=530 \mathrm{~nm}$, reflected by the interference filter 11 , is used for the formation of polarization holograms, and the light of all remaining wavelengths transmitted through the polarizing filter 11 is fed to the double monochromator 13 by means of the collecting objective 12. Double monochromatization allows to get rid of stray light, and the image of the investigated part of the spectrum falls on the fiber matrix 14, which makes it possible tune in «to the allocation of satellite lines of various polluting gases. From the array of light guides 14 the analyzed part of the spectrum through the matching optical system 15 is fed to the computer 16 for registration and processing.

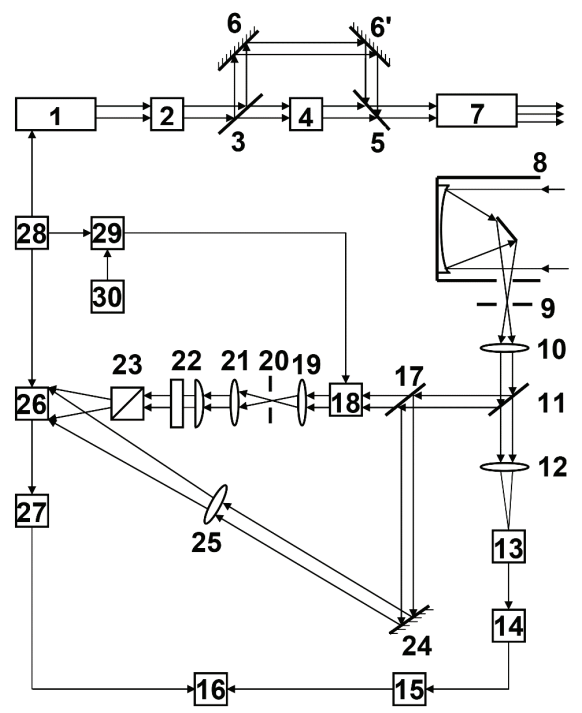

Fig. 2. Block diagram of a gas aerosol holographic lidar

The aerosol channel of the gas-aerosol holographic lidar under consideration makes it possible to study atmospheric aerosol directly by analyzing the images of particles contained in the probed air volume. For this purpose, a method was developed for recording holograms of a focused image with 
energetically enhanced focused reference signals formed by dividing the reflected radiation by intensity, polarization, or wave front [19-21]. This method makes it possible not only to use lasers with a limited coherence length, but also to compensate for the effect of atmospheric turbulence on image quality.

In the diagram shown in Fig. 2 gas-aerosol holographic lidar uses a combined method of dividing reflected radiation by intensity and polarization. For this purpose, the radiation with a wavelength $\lambda_{1}=530 \mathrm{~nm}$, selected with the help of a reflective interference filter 11, is divided by intensity with the help of a semitransparent mirror 17 and directed into two channels - an object and a reference. In the reference channel, the radiation is amplified by an optical quantum amplifier (OQA) 18 and is focused by the lens 19 into the plane of the diaphragm 20, with the help of which the necessary spatial filtering of the reference oscillations is performed [22].

The optical quantum amplifier 18 is triggered by the power supply unit 29 with the help of pulses coming from the output of the synchronizer 28 , which delay the probe pulses relative to the time delay of the signals scattered by the aerosol. In the control unit 30, a control voltage is generated, with the help of which the gain of the OQA is controlled, maintaining the required power ratio of the reference and object signals in the plane of the hologram formation.

To separate the reflected radiation by polarization and obtain polarization holograms of the probed air volume, the reference beam is fed with the help of a matching objective 21 to crossed cylindrical lenses 22, forming a beam with a rectangular cross section, and then directed to a polarization prism 23. The polarization prism 23 creates a reference beam at the output, containing a set of linearly polarized components with a continuously varying azimuth in the plane of hologram formation [23, 24].

The object signal is directed by the semi-transparent mirror 17 to the reflector 24, passes through the lens 25 and enters the input of the hologram forming unit 26, where it interferes with the reference oscillations. The hologram forming unit 26 is triggered from the synchronizer 28 . Since the polarization of the reference oscillations is different, the interference will occur only in those regions of the hologram forming plane where the polarizations of the reference and object signals coincide.

Since the state of polarization does not change upon reflection from a liquid-drop aerosol, and depolarization occurs upon reflection from solid particles, images of qualitatively different aerosol particles are formed on spatially separated areas of the hologram. This makes it possible with the help of the image reconstruction unit 27 and the computer 16 to conduct an automatic separate counting of aerosol particles with different physical properties. Thus, lidar holography, which makes it possible to determine the counting concentration and other parameters directly from the analysis of images of particles in atmospheric air, is currently the only remote method that does not require the introduction of any a priori information about the aerosol under study.

\section{Research results}

6.1. Efficiency evaluation of the GHL SRS channel. Efficiency evaluation of the developed SRS channel of the gas aerosol holographic lidar (GHL) was carried out using formula (2) for some of the most common air pollutants (CO, $\mathrm{NO}_{2}, \mathrm{SO}_{2}, \mathrm{CH}_{4}, \mathrm{H}_{2} \mathrm{~S}, \mathrm{C}_{2} \mathrm{H}_{6}$ ). Below are the technical parameters of the developed lidar system, which were taken for the calculations.

The pulse energy of the fundamental harmonic of a neodymium laser is $500 \mathrm{~mJ}$, the duration is $6 \mathrm{~ns}$, and the pulse repetition rate is $100 \mathrm{~Hz}$. The pulse energy at a wavelength of $\lambda_{2}=265 \mathrm{~nm}$ is $100 \mathrm{~mJ}$.

The receiving aperture diameter of the telescope was chosen to be $500 \mathrm{~mm}$. The average transmittance of the optics of the transmit-receive system of the lidar at wavelengths from $250 \mathrm{~nm}$ to $290 \mathrm{~nm}$ was taken equal to $50 \%$.

The used spectrometer «Ocean-FX» (USA) is equipped with a CMOS matrix (CMOS - complementary metaloxide-semiconductor) «Hamamatsu S11639» (Japan) [25], which has increased quantum efficiency in the ultraviolet (UV) range (from $45 \%$ and more depending on the wavelength). For calculations, the value of $\eta$ was taken in the range from $250 \mathrm{~nm}$ to $290 \mathrm{~nm}$, equal to $40 \%$. The signal-to-noise ratio in the used spectrometer with a single scan is $400: 1$.

In computer modeling of the operation of the SRS lidar, the exponential dependence of the atmospheric density on altitude can be neglected (5), since the device being developed is intended for sounding the surface layer of the atmosphere at altitudes of the order of a kilometer. At such altitudes, the density of the atmosphere can be considered constant and taken as a unit. The calculations were carried out for a transparent atmosphere, in which the scattering from the background aerosol is approximately equal to the molecular scattering [26] determined by formula (4).

Calculations have been made for a number of common pollutant gases. At the same time, the content of $\mathrm{CO}$, $\mathrm{NO}_{2}, \mathrm{SO}_{2}, \mathrm{H}_{2} \mathrm{~S}, \mathrm{C}_{6} \mathrm{H}_{6}$ in the atmosphere was taken at the level of maximum permissible concentrations (MPC) in the working area of the enterprise [27]. The concentrations and combination shifts used for the calculations for the listed polluting gases are given in Table 1.

Table 1

Concentrations and combination frequency shifts of pollutant gases used for calculations

\begin{tabular}{|c|c|c|c|}
\hline \multirow{2}{*}{ Gas } & \multirow{2}{*}{$\begin{array}{c}\text { Raman frequency } \\
\text { shift }\left(\mathrm{cm}^{-1}\right)[28]\end{array}$} & \multicolumn{2}{|c|}{ Concentration } \\
\cline { 3 - 4 } & 2145 & 20 & 17.2 \\
\hline $\mathrm{CO}$ & 1320 & 5 & 2.6 \\
\hline $\mathrm{NO}_{2}$ & 1151.1 & 10 & 3.8 \\
\hline $\mathrm{SO}_{2}$ & 2914 & 30 & 45.1 \\
\hline $\mathrm{CH}_{4}$ & 2611 & 10 & 7.1 \\
\hline $\mathrm{H}_{2} \mathrm{~S}$ & 3072 & 15 & 6.2 \\
\hline $\mathrm{C}_{2} \mathrm{H}_{6}$ & & & \\
\hline
\end{tabular}

The mass concentration of nitrogen in the surface layer of the standard atmosphere was taken equal to $75.51 \%$ [29].

Estimated calculations of the lidar efficiency were carried out using formula (2) under the assumption that the sounding path is homogeneous. In this case, the aerosol and molecular scattering coefficients under the integral sign are constants, so that integration over the spatial coordinate gives only the distance to the probing point. Fig. 3, 4 show the results of calculations for the sounding path from $50 \mathrm{~m}$ to $200 \mathrm{~m}$. 


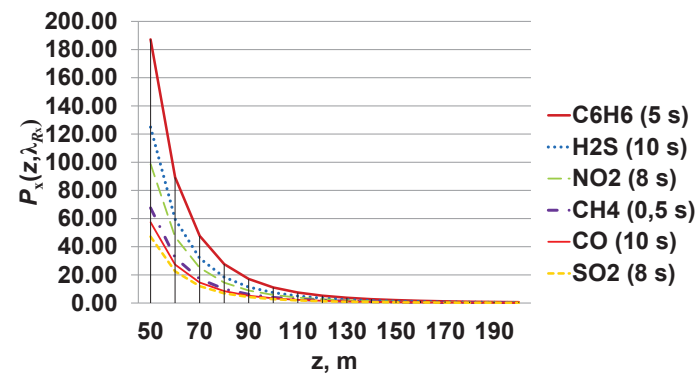

Fig. 3. The number of photoelectrons $P_{x}\left(z, \lambda_{B x}\right)$ registered by the lidar system depending on the distance to the probing point $(z)$ for various gases under study

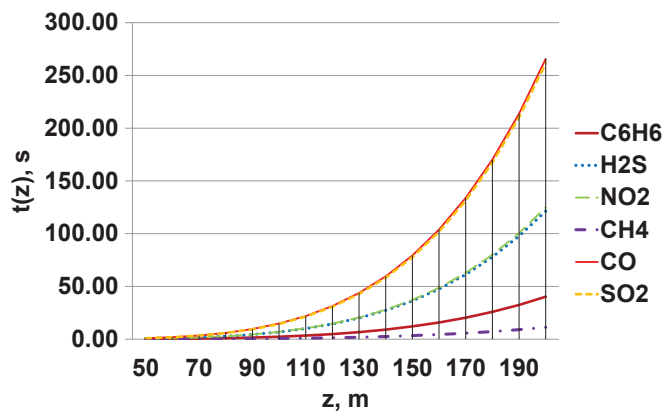

Fig. 4. Dependence of the detection time of the polluting gases under study on the distance to the sounding point

In the computer simulation of the lidar operation in the signal accumulation mode, it was taken into account that the value $n_{0}$ included in formula (2) is determined not only by expression (3), but also in proportion to the accumulation time. Since different gases have different values of the SRS reciprocal cross section $\left(\sigma_{R}\right)$ and, in addition, the calculations were carried out for concentrations that are different for different gases (Table 1), to achieve approximately the same results for different gases, different signal accumulation times are required. This is clearly seen in Fig. 3, where next to the chemical formula of polluting gases in parentheses is indicated the accumulation time of the signal for which the presented graphs were calculated.

Taking into account that $n_{0}$ is proportional to the signal accumulation time, let's also calculated the dependence of the detection time of the polluting gases under study on the distance to the probing point, which are shown in Fig. 4. As can be seen from the graphs in Fig. 4, the required signal accumulation time increases sharply with distance according to a law close to a square law. Calculations have shown that in order to detect the polluting gases under study at their concentration equal to the MPC in the working area of the enterprise, at a distance of half a kilometer, it is required to carry out the signal accumulation mode for tens of minutes. For example, it will take 10 minutes to detect $\mathrm{CH}_{4}$, and 36 minutes to detect $\mathrm{C}_{6} \mathrm{H}_{6}$. This, of course, reduces the efficiency of the developed lidar system and makes it problematic to construct a three-dimensional spatial distribution of the determined gas, since in the presence of wind, the air masses will mix in tens of minutes. However, as can be seen from the graphs in Fig. 4, with a detection range of $200 \mathrm{~m}$, the accumulation mode for the investigated gases is from 11 seconds (for $\mathrm{CH}_{4}$ ) to 4 minutes (for $\mathrm{CO}$ ). This is quite acceptable from the point of view of the efficiency of the measurements carried out by the lidar.
6.2. Metrological support of the information processing system of informative parameters of LDAG and GHL. The laser complex, which includes LDAG and GHL systems, belongs to the field of environmental protection, which become between man and nature and largely determine both their interaction and the very coexistence of man and nature. LDAG and GHL systems are distributed in space, have a complex hierarchical structure and include measuring, computing and control elements that are interconnected by communication channels. The complexity of LDAG and GHL systems makes it necessary to meet the requirements for increased measurement accuracy. In LDAG and GHL systems, a fundamentally different approach to solving the problem of increasing accuracy is used - constructive and structural-algorithmic methods. Constructive is based on the use of stable elements, materials, improvement of production technology. The structural-algorithmic method of increasing the accuracy is based on the introduction of test influences into the measuring transducer, which allow obtaining information not only about the measured value, but also about errors for correcting the conversion function and increasing the measurement accuracy [30]. The solution of the assigned tasks is achieved through the introduction of metrological support for LDAG and GHL systems.

Metrological support of LDAG and GHL systems is «the installation and application of scientific and organizational foundations, hardware and software, rules and regulations in order to ensure the specified accuracy of measurements and specified accuracy of control actions» [31]. One of the important tasks of increasing the accuracy of LDAG and GHL is the introduction of metrological support for the information processing system. LDAG and GHL are information systems, therefore the characteristics of accuracy and the probability of obtaining information are fundamental.

Information is a fundamental quantity, it can't be expressed through other basic quantities. Information includes the content of the system about itself and is an internal property. Mathematically, information $I$ is defined as a measure of the ordering of a set that consists of different objects. The measure of information $I$ associated with a system that can assume $N$ possible states is $\log _{2} N$ and is measured in bits. The information equation is valid if different states are equally probable [32].

The content of the information model of a parameter is a set (unity) of the content of the stochastic and deterministic parts, which determine the numerical value of the possible states of the parameter relative to the sensitivity threshold and the probability of transition from one state to another. The stochastic part of such a model carries the information of the uncertainty of the sensitivity threshold of the informative parameter, and the deterministic one carries the numerical value of the possible states of these parameters.

The methodology of information modeling of an informative parameter is based on the «display» of properties of some nature, which are identified as a manifestation of the intensity of physical quantities, the place and time of their manifestation in the form of a model.

The principle of the information processing system in LDAG and GHL is based on a fundamental approach using information from the quantum components of metrological parameters of physical quantities (decision of the International Committee of Weights and Measures of May 20, 2019). 
The use in information processing systems of the quantum components of the metrological parameters of the LDAG and GHL automatically gives the absolute calculation error, which depends on the number of received decimal places of the numerical value of the parameter information [33].

\section{SWOT analysis of research results}

Strengths. The strengths of the development are the use of various spectral methods, which provides an integrated approach to solving the problems of environmental monitoring of the surface layer of the atmosphere in residential areas and industrial zones of large cities. LDAG allows detecting low concentrations of polluting gases along a stationary sounding path and is suitable for use in residential areas of a modern city. GHL provides the ability to obtain, within a few minutes, three-dimensional images of the distribution of gaseous and aerosol components of atmospheric air with a spatial resolution of about $1 \mathrm{~m}$. This will allow the use of GHL in industrial areas for reliable and prompt determination of penalties against enterprises that violate environmental standards.

Weaknesses. The disadvantages of the work performed include the fact that at this stage, computer modeling of only one gas-analyzing SRS channel of the GHL was carried out. Computer simulation of the GHL aerosol channel was not carried out due to the complexity of the physicomathematical description of the process of registration and processing of information about aerosols by lidar holography methods.

Opportunities. The problems of operational remote monitoring of the atmosphere are acute not only for Ukraine, but also for all industrialized countries. The developed mobile laser complex, when introduced into practice, is capable of ensuring timely detection of sources of atmospheric pollution with high accuracy in order to improve the ecological situation in large cities and prevent environmental disasters.

Threats. Difficulties in the implementation of the results of this development into practice are associated, first of all, with the need to develop technological documentation for the manufacture of original components in accordance with the LDAG and GHL schemes. In addition, the creation of an industrial design of the developed laser complex requires a fairly significant investment, since the complex includes expensive parts and equipment.

\section{Conclusions}

1. The analysis of the physical principles of the interaction of laser radiation with the components of the atmosphere shows the following. The differential absorption method is effective for determining the average concentration of pollutant gases along a fixed sounding path when it is necessary to determine the presence of small amounts of the most common pollutants. This method can be successfully applied for environmental monitoring of the state of the air environment within city blocks, which are quite remote from industrial facilities.

The spontaneous Raman scattering (SRS) method is effective in determining the spatial distribution of polluting gases with a good spatial resolution (of the order of one meter) at relatively short distances (up to $1 \mathrm{~km}$ ).
At the same time, the list of detected gases is not structurally limited by anything. This method makes it possible to identify pollution sources quickly enough and with good spatial accuracy. Therefore, the SRS method can be successfully applied for environmental monitoring of the surface layer of the atmosphere in the industrial zone of large metropolitan areas.

The most effective methods for determining the type and countable concentration of aerosols are lidar holography methods developed in the laboratory of radio and optical holography of V. N. Karazin Kharkiv National University. These methods allow for separate automatic counting of liquid-droplet and solid (dust, soot) aerosol particles in the investigated volume of atmospheric air directly from the analysis of their images. The images of aerosol particles are reconstructed from the registered holograms of the probed airspace area.

2. The schematic diagrams of a laser gas analyzer of differential absorption (LDAG) and a gas-aerosol holographic lidar (GHL) have been developed. In LDAG, in practice, the physical principle of absorption of a quantum of light energy with a certain frequency by the molecules of the studied gas is realized. In the GHL, to determine the gas composition of air, the method of spontaneous Raman scattering (SRS) of a light quantum by molecules of atmospheric gases is implemented in practice. To obtain information about aerosols that make up the studied area of the atmosphere, the GHL implements original methods of lidar holography.

Efficiency evaluation of the GHL gas-analyzing channel was carried out by means of computer modeling of the process of detecting a number of the most common polluting gases. The estimation was carried out for the case when the diameter of the receiving aperture of the GHL telescope is $500 \mathrm{~mm}$, and the energy of the probing pulse is $100 \mathrm{~mJ}$. Computer modeling showed that with such parameters, the GHL provides the detection of pollutants in the surface layer of the atmosphere at the level of ppm units with a detection range of up to $200 \mathrm{~m}$ with a resolution of $1 \mathrm{~m}$ and signal accumulation from $10 \mathrm{~s}$ to $4 \mathrm{~min}$.

3. The description of the basic principles of metrological support of the information processing system in the created laser complex for environmental monitoring of the surface layer of the atmosphere is carried out. It is concluded that the complexity of the LDAG and GHL systems imposes increased requirements on the measurement accuracy. In the created laser complex, an increase in the measurement accuracy is achieved both structurally and through the introduction of metrological support for LDAG and GHL systems.

\section{References}

1. Krekov, G. M., Matvienko, G. G. (2010). Razvitie lazernykh tekhnologii v probleme distantsionnogo zondirovaniia atmosfery. Optika atmosfery i okeana, 23 (10), 865-844.

2. Ruzankina, J., Elizarov, V., Konopel'ko, L., Zhevlakov, A., Grishkanich, A. (2018). Raman lidar with for geoecological monitoring. Journal of Physics: Conference Series, 1124, 051036. doi: http:// doi.org/10.1088/1742-6596/1124/5/051036

3. Wandinger, U. (2005). Introduction to Lidar. Lidar: RangeResolved Optical Remote Sensing of the Atmosphere. Springer, 1-18. doi: http://doi.org/10.1007/0-387-25101-4_1

4. Alimov, S. V., Kascheev, S. V., Kosachev, D. V., Petrov, S. B., Zheviakov, A. P. (2007). Multifunctional lidar for needs of oiland-gas pipes. Proc. of SPIE, 6610. doi: http://doi.org/10.1117/ 12.739830 
5. Ismail, S., Browell, E. V. (2015). Differential absorption lidar. Encyclopedia of Atmospheric Sciences, 277-288. doi: http://doi.org/ 10.1016/b978-0-12-382225-3.00204-8

6. Amediek, A., Ehret, G., Fix, A., Wirth, M., Büdenbender, C., Quatrevalet, M. et. al. (2017). CHARM-F - a new airborne integrated-path differential-absorption lidar for carbon dioxide and methane observations: measurement performance and quantification of strong point source emissions. Applied Optics, 56 (18), 5182-5197. doi: http://doi.org/10.1364/ao.56.005182

7. Wagner, G. A., Plusquellic, D. F. (2016). Ground-based, integrated path differential absorption LIDAR measurement of CO_2, CH_4, and H_2O near $16 \mu \mathrm{m}$. Applied Optics, 55 (23), 6292-6310. doi: http://doi.org/10.1364/ao.55.006292

8. Wagner, G. A., Plusquellic, D. F. (2018). Multi-frequency differential absorption LIDAR system for remote sensing of $\mathrm{CO}_{2}$ and $\mathrm{H}_{2} \mathrm{O}$ near $16 \mu \mathrm{m}$. Optics Express, 26 (15), 19420-19434. doi: http://doi.org/10.1364/oe.26.019420

9. Shiina, T. (2018). Hydrogen gas detection by mini-Raman lidar Ionizing Radiation Effects and Applications. Books on Demand, $41-60$

10. Kim, D., Lee, H. (2019). Development of Raman Lidar for Remote Sensing of CO2 Leakage at an Artificial Carbon storage experimental site. Geophysical Research Abstracts, 21.

11. Kim, D., Kang, H., Ryu, J.-Y., Jun, S.-C., Yun, S.-T., Choi, S. et. al. (2018). Development of Raman Lidar for Remote Sensing of $\mathrm{CO}_{2}$ Leakage at an Artificial Carbon Capture and Storage Site. Remote Sensing, 10 (9), 1439. doi: http://doi.org/ $10.3390 / \mathrm{rs} 10091439$

12. Astmann, A., Müller, D. (2005). Lidar and atmospheric aerosol particles. Lidar: Range-Resolved Optical Remote Sensing of the Atmosphere. Springer, 105-142. doi: http://doi.org/10.1007/ 0-387-25101-4_4

13. Matvienko, G. G., Banakh, V. A., Bobrovnikov, S. M., Burlakov, V. D., Veretennikov, V. V., Kaul, B. V. et. al. (2009). Razvitie tekhnologii lazernogo zondirovaniia atmosfery. Optika atmosfery i okeana, 22 (10), 915-930.

14. Volkov, N. N. (2012). Vybor parametrov mnogovolnovogo aerozolnogo lidara dlia distantsionnogo zondirovaniia atmosfery. Nauchno-tekhnicheskii vestnik Sankt-Peterburgskogo gosudarstvennogo universiteta informatsionnykh tekhnologii, mekhaniki i optiki, 1 (77), 6-9.

15. Gimmestad, G. G. (2005). Differential-absorption lidar for ozone and industrial emissions. Lidar: Range-Resolved Optical Remote Sensing of the Atmosphere. Springer, 187-212. doi: http://doi.org/ 10.1007/0-387-25101-4 7

16. Wandinger, U. (2005). Raman lidar. Lidar: Range-Resolved Optical Remote Sensing of the Atmosphere. Springer, 241-271. doi: http:// doi.org/10.1007/0-387-25101-4_9

17. Nishita, T., Sirai, T., Tadamura, K., Nakamae, E. (1993). Display of the earth taking into account atmospheric scattering. Proceedings of the 20th Annual Conference on Computer graphics and interactive techniques (SIGGRAPH '93). Anaheim, 175-182. doi: http://doi.org/10.1145/166117.166140

18. Deirmendjian, D. (1969). Electromagnetic scattering on spherical polydispersions. American Elsevier Pub. Co, 290.

19. Safronov, G. S., Titar, V. P. (1994). Opticheskii lokator. Patent No. 944437 RF

20. Titar, V. P., Shpachenko, O. V. (2001). Poliarizatsionnye golograficheskie metody lidarnogo kontrolia za sostoianiem atmosfery. Elektromagnitnye iavleniia, 2 (1 (5)), 111-117.
21. Tytar, V. P., Shpachenko, O. V. (2001). Holohrafycheskyi lydar dlia ekolohycheskoho monytorynha atmosferi. Visnyk khakrivskoho natsionalnoho universytetu im. V. N. Karazina. No. 513 Radiofizyka ta elektronika, 1, 151-160.

22. Safronov, G. S., Titar, V. P. (1994). Opticheskii lokator. Patent No. 743401 RF

23. Sogokon, A. B., Titar, V. P. (1983). Golograficheskoe ustroistvo. A. C. No. 1149206 SSSR

24. Safronov, G. S., Sogokon, A. B., Titar, V. P. (1980). Sposob golograficheskoi identifikatsii materialov udalennykh obektov. A. S. No. 678969 SSSR.

25. Hamamatsu Image Sensors. Selection guide (2019). Available at: https://www.hamamatsu.com/resources/pdf/ssd/image_sensor_kmpd0002e.pdf

26. Razenkov, I. A. (2013). Aerozolnii lidar dlia nepreryvnykh atmosfernykh nabliudenii. Optika atmosfery i okeana, 26 (1), 52-63.

27. Hranychno dopustymi kontsentratsii (HDK) khimichnykh chynnykiv u povitri robochoi zony, zatverdzheni HDSL vid 17.07.2015. Available at: http://normativ.ua/sanpin/tdoc27838.php

28. Measures, R. M. (1992). Laser remote sensing: fundamentals and applications. Malabar: Krieger Publishing Co., 510.

29. Sorokhtin, O. G., Ushakov, S. A. (2002). Razvitie Zemli. Moscow: Izd-vo MGU, 506.

30. Tuz, Iu. M. (1976). Strukturnye metody povysheniia tochnosti izmeritelnykh ustroisto. Kyiv: Vischa shkola. Golovnoe izd-vo, 127.

31. DSTU 2682-94. Metrolohichne zabezpechennia (1994). Osnovn polozhennia. Vvedenyi 26.07.94. Kyiv: Derzh standart Ukrainy, 439.

32. Olson, G., Piani, D. (2001). Tsifrovye sistemy avtomatizatsi $i$ upravleniia. Saint Petersburg: Nevskii dialekt, 557.

33. Ruzhentsev, Y. V., Lutskyi, S. V., Fetkyv, V. P., Podzyhun, O. I. (2017). Discrete probabilistic information laws factor of efficiency. Ukrainskyi metrolohichnyi zhurnal, 1, 67-71.

Titar Vladimir, PhD, Head of Laboratory of Radio and Optical Holography, V. N. Karazin Kharkiv National University, Ukraine, e-mail:inhol@ukr.net, ORCID:http://orcid.org/0000-0002-4874-8929

Shpachenko Olga, Researcher, Laboratory of Radio and Optical Holography, V. N. Karazin Kharkiv National University, Ukraine, e-mail: shpachenkoov@gmail.com, ORCID: http://orcid.org/00000002-6072-5340

Panimarchuk Oksana, PhD, Assistant, Department of Medical and Pharmaceutical Chemistry, Bukovinian State Medical University, Chernivtsi, Ukraine, e-mail: panimarchuk@bsmu.edu.ua, ORCID: http:// orcid.org/0000-0002-2184-3280

Guzenko Mykhailo, Head of Department, Institute of Holography of Academy of Science of Applied Radioelectronics, Kharkiv, Ukraine, e-mail: mikhailgyzenko@ukr.net, ORCID: http://orcid.org/ 0000-0001-9703-4482

Koshman Sergii, Director, LLC «GREENSOL», Poltava, Ukraine, e-mail: greensol.ua@gmail.com, ORCID: http://orcid.org/0000-00018772-0956

Lutsky Sergey, PhD, Senior Lecturer, Department of Metrology and Technical Expertise, Kharkiv National University of Radio Electronics, Ukraine, e-mail: lutsk.sv6@gmail.com,ORCID: http://orcid.org/ 0000-0002-5327-6591 